\title{
Activin A induction of FSH $\beta$ subunit transcription requires SMAD4 in immortalized gonadotropes
}

\author{
Ying Wang, Vanessa Libasci and Daniel J Bernard \\ Department of Pharmacology and Therapeutics, McGill University, 3655 Promenade Sir William Osler, Montréal, Quebec, Canada H3G 1Y6 \\ (Correspondence should be addressed to D J Bernard; Email: daniel.bernard@mcgill.ca)
}

\begin{abstract}
Activins regulate FSH synthesis by stimulating the phosphorylation and nuclear accumulation of SMAD2 and SMAD3, which bind to a consensus SMAD-binding element in the proximal murine FSH $\beta$ (Fshb) subunit gene to drive transcription. Previous over-expression and in vitro DNA binding analyses suggested that SMAD4 participates in complexes with SMAD2 and SMAD3 to regulate Fshb expression. Here, we have characterized the role of endogenous SMAD4 in activin A induction of Fshb transcription in immortalized murine gonadotropes (L $\beta T 2$ ). We identified five murine Smad4 mRNA isoforms, of which, four are newly described; however, the canonical full-length form predominated at both the mRNA and protein levels. Depletion of endogenous SMAD4 by RNA interference (RNAi) abolished activin A-induced Fshb promoter-reporter activity and greatly attenuated constitutively active activin type IB receptor-stimulated Fshb mRNA levels. The activin A response was rescued with an RNAi-resistant form of wild-type SMAD4, but not with a DNA-binding-deficient (Lys88Arg) SMAD4, suggesting that DNA binding by SMAD4 is necessary for activin induction of the Fshb gene. Though SMAD2 and SMAD3 are generally thought to partner with SMAD4 prior to accumulation in the nucleus, treatment with leptomycin B, an inhibitor of SMAD4 nuclear export, reduced but did not prevent activin A induction of Fshb mRNA levels or promoter activity. In addition, a constitutively nuclear form of SMAD4 rescued the effect of endogenous SMAD4 depletion. Collectively, these data demonstrate a necessary role for SMAD4 in activin A induction of the murine Fshb gene in immortalized gonadotropes.
\end{abstract}

Journal of Molecular Endocrinology (2010) 44, 349-362

\section{Introduction}

Activins were initially characterized as stimulators of FSH secretion from rat pituitary cultures (Ling et al. 1986a,b, Vale et al. 1986). Subsequent studies demonstrated that they produce this effect, at least in part, by stimulating the transcription of the $\mathrm{FSH} \beta(F s h b)$ subunit gene, which is the rate-limiting step in the synthesis of the mature dimeric hormone (Attardi \& Miklos 1990, Weiss et al. 1995). The mechanisms through which activins regulate $F s h b$ were elusive until recently. The development of the murine gonadotrope cell line, L $\beta$ T2 (Alarid et al. 1996), has greatly facilitated the investigations of $F s h b$ transcription basally and in response to activins, other peptides, and steroid hormones (Pernasetti et al. 2001, Suszko et al. 2003, Bernard 2004, Thackray et al. 2006). This remains the only homologous cell line currently available for the investigations of $F s h b$ transcriptional regulation.

Like other proteins in the transforming growth factor $\beta$ (TGF $\beta$ ) superfamily, activins signal through heteromeric complexes of type I and type II serine/threonine receptor kinases (Tsuchida et al. 2009). The importance of the activin type II receptor (ACVR2) and, by inference, activins to in vivo regulation of FSH synthesis is underscored by depleted FSH levels and infertility observed in Acur2-deficient mice (Matzuk et al. 1995). ACVR2 and the related ACVR2B trans-phosphorylate and activate the type I receptor, activin receptor-like kinase 4 (ALK4 or ACVR1B), upon activin binding. Inhibition of ALK4 activity with the small molecule inhibitor SB431542 (Inman et al. 2002) demonstrates the necessary role for ALK4 in activin A induction of Fshb promoter-reporter activity and mRNA expression (Lee et al. (2007) and Y Wang, V Libasci and DJ Bernard, unpublished observations). Activated ALK4 propagates intracellular signaling via phosphorylation of effector proteins, the most thoroughly investigated of which are the SMAD proteins, SMAD2 and SMAD3. C-terminally phosphorylated SMADs partner with a co-factor, SMAD4, and accumulate in the nucleus where they regulate target gene transcription, often through direct binding of SMADs to cis-regulatory elements, the so-called SMAD-binding elements (SBEs). Activins stimulate SMAD2/3 phosphorylation and nuclear accumulation in LBT2 cells. Depletion of endogenous SMAD2 or SMAD3 by RNA interference (RNAi) attenuates activin-stimulated $F s h b$ transcription (Bernard 2004, Suszko et al. 2005, Lamba et al. 2006).

DOI: 10.1677/JME-09-0142 Online version via http://www.endocrinology-journals.org 
The murine and rat Fshb promoters possess a consensus 8-bp SBE within $\sim 270$ bp of the transcription start site. Complexes of SMAD2, SMAD3, and SMAD4 can bind to this element in an activin-regulated fashion in vitro, and mutation of the SBE attenuates both activin- and SMAD-regulated transcription in LßT2 cells (Suszko et al. 2003, Gregory et al. 2005, Lamba et al. 2006, McGillivray et al. 2007). Though both over-expression and in vitro binding experiments strongly implicate SMAD4 in the activin induction of $F s h b$, a definitive role for the endogenous protein has not yet been demonstrated in vivo or in cell models. Here, we have characterized the expression of SMAD4 in L $\beta$ T2 cells and shown a necessary role for the protein in activin induction of murine Fshb transcription. Moreover, our findings suggest that SMAD4 binds to DNA to mediate its effects, and that constitutively nuclear SMAD4 is sufficient to mediate the activin response.

\section{Materials and methods}

\section{Reagents}

Human recombinant activin A and TGF $\beta 1$ were purchased from R\&D systems (Minneapolis, MN, USA). DMEM with glucose $(4.5 \mathrm{~g} / \mathrm{l})$, L-glutamine, and sodium pyruvate was obtained from Wisent Inc. (St-Bruno, Quebec, Canada). DMEM/F-12 Ham's medium (1:1) with $2.5 \mathrm{mmol} / \mathrm{l} \mathrm{L}$-glutamine and $15 \mathrm{mmol} / \mathrm{l}$ HEPES was obtained from HyClone Laboratories (South Logan, UT, USA). TRIzol, 4-12\% NuPAGE gels, SYBR Green Quantitative PCR Master Mix, gentamicin, Lipofectamine/Plus, Lipofectamine 2000, fetal bovine serum (FBS), goat anti-mouse Alexa Fluor 555 (A-21424), and ProLong Gold antifade reagent with 4',6-diamidino-2-phenylindole (DAPI) (P-36935) were obtained from Invitrogen. The mouse anti-human SMAD4 (SC-7966) and rabbit anti-mouse SMAD4 (06-693) antibodies were obtained from Santa Cruz Biotech (Santa Cruz, CA, USA) and Upstate Biotech (Millipore, Billerica, MA, USA) respectively. Polyclonal (F7425) and mouse monoclonal (F3165) anti-FLAG antibodies, cycloheximide (CHX), dithiothreitol (DTT), SB431542, and GnRH1 were obtained from Sigma Chemical Co. Normal goat serum (NGS) was obtained from Vector Laboratories (Burlingame, CA, USA). Leptomycin B (LMB) was obtained from Calbiochem (Gibbstown, NJ, USA). dNTPs, GoTaq Flexi DNA polymerase, MMLV-RT, random hexamers, $5 \times$ passive lysis buffer (PLB), T4 DNA ligase, restriction endonucleases, and pGEM-T Easy cloning reagents were purchased from Promega Corp. Pfu Turbo and $P f u$ Ultra polymerases were obtained from Stratagene (La Jolla, CA, USA). Protease inhibitor tablets (Complete Mini) and ATP were obtained from Roche. Oligonucleotides were synthesized by Integrated
DNA Technologies (Coralville, IA, USA). ECL and ECL-Plus reagents were obtained from GE Healthcare (Piscataway, NJ, USA). $\left[\gamma_{-}{ }^{32} \mathrm{P}\right]$ ATP and $\left[\alpha_{-}{ }^{32} \mathrm{P}\right] \mathrm{dCTP}$ were obtained from PerkinElmer (Boston, MA, USA). Smad4 (siGENOME D-040687-01 and D-040687-02) and control (siGENOME non-targeting short interfering RNA (siRNA) \#5 D-001210-05) siRNAs were obtained from Dharmacon (Lafayette, CO, USA). D-luciferin potassium salt was obtained from BD Pharmingen (Mississauga, Ontario, Canada). Matrigel was obtained from BD Biosciences (Bedford, MA, USA).

\section{Cell lines}

LRT2 (murine pituitary tumor-derived gonadotropes; contributed by Dr Pamela Mellon, University of California-San Diego, USA; Alarid et al. 1996), SW480.7 (human SMAD4-deficient colon carcinoma; contributed by Dr Fang Liu, Rutgers University, USA; Goyette et al. 1992, Calonge \& Massague 1999), and NIH3T3 (murine embryonic fibroblasts; contributed by Dr Patricia Morris, Population Council, New York, NY, USA; Jainchill et al. 1969) cells were cultured in DMEM with $10 \%$ (v/v) FBS at $37^{\circ} \mathrm{C}$ and $5 \% \mathrm{CO}_{2}$. Chinese hamster ovary (CHO; also contributed by Dr Morris; Puck et al. 1958) cells were cultured in DME:F12 (1:1) with $10 \%(\mathrm{v} / \mathrm{v}) \mathrm{FBS}$ at $37^{\circ} \mathrm{C}$ and $5 \% \mathrm{CO}_{2}$. Cells in continuous passage were plated in T-75 flasks. For experiments, cells were cultured in 6-, 24-, or 48-well plates or $10-\mathrm{cm}$ dishes as indicated.

\section{Cloning of Smad4 isoforms}

One microgram of L $\beta \mathrm{T} 2$ cell total RNA was reverse transcribed with MMLV-RT, random hexamer primers, and dNTPs as described previously (Bernard 2004). The cDNA was subjected to nested PCR using Pfu Ultra polymerase, dNTPs, and Smad4 primers directed against the start (in exon 2) and stop of translation (in exon 12; see Table 1 for inner and outer primer sequences). The reaction conditions for both rounds of PCR were $95^{\circ} \mathrm{C}$ for $2 \mathrm{~min}$, followed by 30 cycles of $95^{\circ} \mathrm{C}$ for $30 \mathrm{~s}, 54^{\circ} \mathrm{C}$ for $30 \mathrm{~s}, 72^{\circ} \mathrm{C}$ for $1.5 \mathrm{~min}$, followed by a final extension step at $72{ }^{\circ} \mathrm{C}$ for $10 \mathrm{~min}$. The resulting amplicons from the nested PCR were TA cloned (pGEM-T Easy Vector System; Cat. \#A3610; Promega). Recombinants were analyzed by blue-white screening, and plasmids were purified (Qiagen) and sequenced (GenomeQuebec) using standard procedures. The different Smad4 splice variants were then PCR amplified from the clones in pGEM-T Easy and subcloned into a pcDNA3.0 (Invitrogen) vector with an N-terminal FLAG tag (see Table 1 for primer sequences). K88R (Lamba et al. 2006), L146/148A, and siRNA-resistant forms of SMAD4 were generated by site-directed 
Table 1 PCR primers

\begin{tabular}{|c|c|}
\hline Smad4 & \\
\hline Outer & \\
\hline Rev & TCCTGGAAATGGTTAGGGCGT \\
\hline For & ACAATATGTCTATAACAAATACACCA \\
\hline Rev & TCAGTCTAAAGGCTGTGGGT \\
\hline SMAD4 & \\
\hline For & GGCGAATTCCGAGACAATATGTCTATAACAAATACACCA \\
\hline SiRNA & \\
\hline For & GCACTACCACCTGGACTGGAAGTCGAACTGCACCATAC \\
\hline Rev & GTATGGTGCAGTTCGACTTCCAGTCCAGGTGGTAGTGC \\
\hline SMAD & \\
\hline For & TCACCTGGAATTGATCTCTCAGGAGCAACAGCGCAGAGTAATGCTCCAAGTATG \\
\hline Rev & CATACTTGGAGCATTACTCTGCGCTGTTGCTCCTGAGAGATCAATTCCAGGTGA \\
\hline Rpl19 & \\
\hline For & CGGGAATCCAAGAAGATTGA \\
\hline Rev & TTCAGCTTGTGGATGTGCTC \\
\hline Semi-q & \\
\hline Fshb & \\
\hline For & ATGAAGTTGATCCAGCTTTG \\
\hline Rev & CATTTCACTGAAGGAGCAGT \\
\hline Rpl19 & \\
\hline For & CTGAAGGTCAAAGGGAATGTG \\
\hline Rev & GGACAGAGTCTTGATGATCTC \\
\hline
\end{tabular}

${ }^{\mathrm{a}}$ Restriction sites used for cloning are underlined.

mutagenesis (QuikChange protocol; Stratagene; see Table 1 for primer sequences). All clones were verified by sequencing (GenomeQuebec).

\section{Western blotting}

L $\beta$ T2, SW480.7, NIH3T3, and CHO cells were transfected as indicated. Whole cell extracts were prepared in RIPA buffer containing protease inhibitors, and were run on 4-12\% NuPAGE Novex Bis-Tris gels in 2-(N-morpholino) ethanesulfonic acid (MES) running buffer ( $50 \mathrm{mmol} / 1 \mathrm{MES}, 50 \mathrm{mmol} / 1$ Tris base, $0 \cdot 1 \%$ (w/v) SDS, and $1 \mathrm{mmol} / 1$ EDTA, pH 7.3) or $10 \%$ Trisglycine as described previously (Bernard 2004). Proteins were transferred onto nitrocellulose filters, which were first blocked with $5 \%$ (w/v) milk in PBST (137 mM NaCl, 2.7 mM KCl, 10 mM Na $2 \mathrm{HPO}_{4}, 2 \mathrm{mM}$ $\mathrm{KH}_{2} \mathrm{PO}_{4}, \mathrm{pH} 7 \cdot 4$, and $0 \cdot 1 \%(\mathrm{v} / \mathrm{v})$ Tween-20), and were then incubated overnight at $4{ }^{\circ} \mathrm{C}$ with FLAG (1:2000), $\beta$-actin (1:5000), or SMAD4 (1:1000) antibodies as indicated. Blots were washed with PBST three times, and were then incubated in appropriate HRPconjugated secondary antibodies for $1 \mathrm{~h}$, followed by three washes with PBST and incubation in ECL or ECL-Plus reagents (to visualize protein bands by chemiluminescence) prior to exposure to an X-ray film.

\section{Northern blotting}

CHO cells in 10-cm plates were transfected with the different FLAG-SMAD4 isoform expression vectors, and their RNA was extracted using TRIzol. RNA was subjected to northern blot analyses using a $\left[\gamma^{-32} \mathrm{P}\right]$ ATP end-labeled FLAG oligo probe. Subsequently, the blot was stripped and probed with a $\left[\alpha_{-}^{32} \mathrm{P}\right] \mathrm{dCTP}$ randomprime-labeled (Ready-to-Go Beads; Amersham, GE Healthcare) Rpl19 cDNA probe using the methods described by Bernard (2004).

\section{Promoter-reporter assays}

Reporter assays in L $\beta$ T2 cells with the murine $-1990 /+1$ Fshb-luciferase (Bernard 2004), porcine $-326 /+8$ Fshb-luciferase (Lamba et al. 2009), or human $-196 /+9$ LHB-luciferase (Fortin et al. 2009) vectors were performed as described in the previous studies (note: for all reporters, +1 refers to the start of transcription). Briefly, L $\beta$ T2 cells (passages 4-10) were seeded in 24-well plates at a density of 250000 cells/ well $48-72 \mathrm{~h}$ prior to transfection. Cells were then transfected overnight with $450 \mathrm{ng} /$ well of the indicated reporter plasmids using Lipofectamine 2000 (2 $\mu \mathrm{l} /$ well) following the manufacturer's instructions. siRNAs 
were co-transfected at a final concentration of $5 \mathrm{nmol} / \mathrm{l}$. For siRNA-rescue experiments, the indicated SMAD4 constructs were co-transfected at a final concentration of $20 \mathrm{ng}$ /well. After transfection, cells were washed and then incubated overnight in serum-free DMEM. On the following day, cells were treated with a vehicle $\left(\mathrm{H}_{2} \mathrm{O}\right)$, activin A (1 nmol/l), or GnRH1 $(100 \mathrm{nmol} / \mathrm{l})$ for $6 \mathrm{~h}$. Cells were then washed with PBS and lysed in $1 \times$ PLB $(200 \mu \mathrm{l} /$ well). Twenty microliters of lysate were combined with $100 \mu \mathrm{l}$ of assay buffer (final concentrations after addition to $20 \mu \mathrm{l}$ of protein lysates: $15 \mathrm{mM}$ potassium phosphate ( $\mathrm{pH} 7 \cdot 8), 25 \mathrm{mM}$ glycyl glycine, $15 \mathrm{mM} \mathrm{MgSO} 4,4 \mathrm{mM}$ EDTA, $2 \mathrm{mM}$ ATP, $1 \mathrm{mM}$ DTT, $0.04 \mathrm{mM}$ D-luciferin), and luciferase activity was measured on an Orion II microplate luminometer (Berthold, Pforzheim, Germany). We routinely observe the regulation of standard vectors used for transfection efficiency using activins and over-expressed SMADs, thereby precluding their use (data not shown). Others have reported similar results in L $\beta$ T2 cells (Suszko et al. 2003), and still others legitimately question the utility of the approach as a valid measure of transfection efficiency (Bergeron et al. 1995, Howcroft et al. 1997, Siedow et al. 2000, Huszar et al. 2001, Shifera \& Hardin 2010). Normalization by protein content did not modify the results; therefore, only luciferase data obtained from replicate experiments are reported. For reporter assays in SW480.7 cells, cells were seeded in 48-well plates at a concentration of 50000 cells/well. Approximately $48-72 \mathrm{~h}$ after seeding, cells were transfected with $225 \mathrm{ng} /$ well of CAGA-luciferase reporter (Dennler et al. 1998) along with $25 \mathrm{ng} /$ well of FLAG-SMAD3 expression vector (contributed by Dr Teresa Woodruff, Northwestern University, Chicago, IL, USA) and $\pm 25 \mathrm{ng}$ /well of the different SMAD4 isoform expression vectors generated here using Lipofectamine 2000 ( $1 \mu \mathrm{l} /$ well). On the following day, cells were washed and then cultured for an additional $24 \mathrm{~h}$ in serum-free media with or without $1 \mathrm{nmol} / 1$ activin A or $200 \mathrm{pmol} / 1$ TGF $\beta 1$ (not shown). Lysates were prepared, and luciferase assays were performed as in L $\beta$ T2 cells. All reporter assays were performed a minimum of three times, and all treatments were performed three to six times within each experiment. The data obtained from replicate experiments were highly consistent, and were therefore pooled for the purposes of presentation and statistical analyses (see below).

\section{Immunofluorescence and confocal microscopy}

L $\beta$ T2 cells were seeded on Matrigel-coated (final concentration 1:2.6 in media) cover slips (12 mm diameter) in 24-well plates at a density of 200000 cells/ well. After $24 \mathrm{~h}$, cells were serum-starved overnight and were then treated with $2 \mathrm{ng} / \mathrm{ml} \mathrm{LMB}$ or vehicle
$(0.01 \%$ ethanol) for $60 \mathrm{~min}$ or with $1 \mathrm{nmol} / \mathrm{l}$ activin A for $30 \mathrm{~min}$. For co-treatment, LMB was applied for 60 min prior to 30-min activin A treatment. Cells were fixed in $2 \%$ paraformaldehyde for $20 \mathrm{~min}$, washed three times with PBS, blocked in 5\% (v/v) NGS $/ 0 \cdot 2 \%$ $(\mathrm{v} / \mathrm{v})$ Triton X-100 in PBS at room temperature for $1 \mathrm{~h}$, and incubated in mouse IgG (Upstate/Millipore) or mouse anti-SMAD4 diluted $1: 50$ in $1 \%(\mathrm{v} / \mathrm{v})$ NGS $/ 0 \cdot 04 \%$ (v/v) Triton X-100 overnight at $4{ }^{\circ} \mathrm{C}$. Cells were then washed with PBS three times and incubated for $1 \mathrm{~h}$ at room temperature in goat antimouse Alexa Fluor 555 diluted 1:500 in 1\% (v/v) NGS $/ 0 \cdot 04 \%(\mathrm{v} / \mathrm{v})$ Triton X-100. After washing three times with PBS, cover slips were mounted onto microscope slides in ProLong Gold antifade reagent with DAPI. Cells were visualized using a LSM-510 META laser-scanning confocal microscope (Zeiss, Jena, Germany; plan-Apochromat $63 \times / 1 \cdot 4$ oil immersion), and images were captured using Zeiss LSM Image Browser software (version 4.3). Excitation and emission spectra for Alexa 555 and DAPI were $543 \mathrm{~nm} / 560 \mathrm{~nm}$ (long pass) and $405 \mathrm{~nm} / 420-480 \mathrm{~nm}$ (band pass) respectively. To quantify SMAD4 nuclear accumulation, we counted DAPI-stained (DAPI +) nuclei in three to six different visual fields. We then counted the number of cells in which the intensity of nuclear SMAD4 signal exceeded that of the cytosolic SMAD4 signal (SMAD4+ nuclei). The proportion of cells showing SMAD4 nuclear accumulation is presented (Table 2) as the ratio of SMAD4+ nuclei to DAPI + nuclei multiplied by 100 . The quantification was performed by one of the investigators, who was blinded to the experimental conditions. To localize the SMAD4-L146/148A mutant, cells were cultured as described and were transfected with $200 \mathrm{ng} /$ well of expression vector using Lipofectamine 2000. After $48 \mathrm{~h}$, cells were fixed and subjected to immunofluorescence analysis using anti-FLAG

Table 2 SMAD4 nuclear accumulation

\begin{tabular}{|c|c|c|c|}
\hline & $\begin{array}{l}\text { DAPI+ } \\
\text { nuclei }^{\mathrm{a}}\end{array}$ & $\begin{array}{l}\text { SMAD4+ } \\
\text { nuclei }^{\text {b }}\end{array}$ & $\begin{array}{l}\text { Percent } \\
\text { nuclear } \\
\text { accumulation }\end{array}$ \\
\hline \multicolumn{4}{|l|}{ Condition } \\
\hline Control & 137 & 2 & 1.5 \\
\hline $0.5 \mathrm{~h}$ activin $\mathrm{A}$ & 192 & 17 & 8.9 \\
\hline $1 \mathrm{~h}$ activin $A$ & 152 & 49 & 32 \\
\hline $2 \mathrm{~h}$ activin $\mathrm{A}$ & 164 & 65 & 40 \\
\hline $4 \mathrm{~h}$ activin $A$ & 138 & 36 & 26 \\
\hline $6 \mathrm{~h}$ activin $A$ & 219 & 83 & 38 \\
\hline $1.5 \mathrm{~h}$ LMB & 160 & 130 & 81 \\
\hline $\begin{array}{l}1.5 \mathrm{~h} \\
\text { LMB/SB431542 }\end{array}$ & 180 & 167 & 93 \\
\hline
\end{tabular}

${ }^{a}$ Number counted.

${ }^{b}$ Number counted among DAPI-labeled cells counted in the first column. ${ }^{\mathrm{C}}($ SMAD4 +/DAPI + $) \times 100$. 
(Sigma, cat\# F3165, 1:1000 dilution) and goat anti-mouse Alexa 555 (1:600 dilution) as primary and secondary antibodies respectively.

\section{Real-time RT-PCR}

L $\beta$ T2 cells seeded in six-well plates $\left(1 \times 10^{6}\right.$ cells/well $)$ were transfected with $1 \mu \mathrm{g} /$ well of pcDNA3.0 or HA-tagged rat ALK4TD (contributed by Dr Teresa Woodruff, Northwestern University, Chicago, IL, USA) in the presence of $5 \mathrm{nmol} / 1$ control or Smad4 siRNA with Lipofectamine/Plus for $6 \mathrm{~h}$ as indicated. Cells were then cultured in complete media for $48 \mathrm{~h}$ prior to extraction of total RNA using TRIzol. Fshb mRNA expression was determined by real-time quantitative RT-PCR using the relative standard curve method and Rpl19for normalization as previously described (Lamba et al. 2009). The same qPCR methodology was used to quantify Fshb mRNA expression shown in Fig. 5B.

\section{Statistical analyses}

In reporter assays, treatments were performed three to six times within each experiment, and experiments were repeated three to five times (as indicated in the figure legends). For the purposes of analysis, treatment replicates within an experiment were averaged to generate $n=1$ per treatment per experiment. The means across the three to five independent experimental replicates were then used in statistical analyses such that $n=3-5$ per treatment. Therefore, the data presented reflect the means of means (+ s.E.M.), where $n$ is the number of experimental replicates. Statistical comparisons were made using one-way (Fig. 3E), two-way (Figs 3B-D and F, 4B and $\mathrm{D}$, and $5 \mathrm{~A}$ and D-E), or three-way (Fig. 1D) ANOVA, and significant $(P<0.05)$ main effects and/or interactions were further analyzed with Tukey's post hoc comparison tests. The reported differences in the figures uniformly reflect the results of pairwise (Tukey's) comparisons following confirmation of statistically significant interactions.

\section{Results}

\section{Differential expression and function of Smad4 isoforms in L $\beta T 2$ cells}

To begin to understand the role of endogenous SMAD4 in gonadotropes, we first characterized the presence and nature of Smad4 isoforms in L $\beta \mathrm{T} 2$ cells. In RT-PCR analysis, using primers directed against the start (exon 2) and end (exon 12) of translation of the canonical (full-length) Smad4, we amplified several fragments from L $\beta$ T2 cDNA (Fig. 1B, lane 2). The full-length isoform (lane 3) corresponded to the most abundant PCR product (lane 2). A second isoform, Smad4 $4^{\Delta e x 6-7}$ (lane 4; GenBank accession no. GU072917), in which exons 6 and 7 were skipped, was similar to one described previously in HaCaT ((Pierreux et al. 2000); referred to as $\operatorname{Smad} 4^{\Delta \mathrm{ex} 5-6}$ therein), MDA-MB-231 (de Winter et al. 1997), and neuroblastoma cells (Kageyama et al. 1998). This splice variant is predicted to encode a SMAD4 protein lacking 79 amino acids (aa) of the linker region. In addition, Trp301 in the fulllength SMAD4 is Arg222 in this form of the protein. In contrast to what has been described previously, the Smad $4^{\mathrm{ex6}-7}$ clones identified here also had a 14-bp insertion relative to the full-length sequence. An alternative $5^{\prime}$ splice donor was used such that $14 \mathrm{bp}$ were included at the end of exon 10 , which were missing in the canonical form. The same $3^{\prime}$ splice acceptor at the end of intron 10 (beginning of exon 11) was used. This leads to a frameshift, in which C-terminal amino acids are lost, including the final 93 amino acids of the Mad homology 2 (MH2) domain, and 45 novel amino acids are introduced (see Fig. 1A for a schematic representation). A BLASTP search of the non-redundant database revealed no sequence identity between these predicted 45 amino acids and any known proteins.

We identified three additional isoforms: $\Delta \operatorname{ex} 6-8$ (Fig. 1B, lane 6), $\Delta$ ex9-10 (lane 7), and $\Delta$ bp13421599 (lane 5). Smad4 ${ }^{\Delta e x 6-8}$ (lane 6; GenBank accession no. GU072918) is predicted to encode a protein lacking 96 amino acids (aa 221-317 of the full-length protein) corresponding to the C-terminus of the linker region and the first three amino acids of the MH2 domain. Serine 222 in the full-length protein is replaced by a threonine. The predicted protein is otherwise in-frame, containing the majority of the MH2 domain (see Fig. 1A). In Smad4 $4^{\operatorname{ex} 9-10}$ (lane 7; GenBank accession no. GU072919), $353 \mathrm{bp}$ were skipped relative to the full-length form. The omission of these bps produces a frameshift. The SMAD4 ${ }^{\Delta \mathrm{ex} 9-10}$ protein is predicted to resemble the full-length SMAD4 through Pro317 (the second amino acid of the MH2 domain) and then diverge with the addition of two novel amino acids (Gly318 and Leu319) followed by a stop codon. As a result, this form of the protein is predicted to lack the MH2 domain and C-terminus (see Fig. 1A). In Smad $4^{\Delta \text { bp 1342-1599 }}$ (lane 5; bps are numbered relative to the first bp in the start codon of the full-length isoform; GenBank accession no. GU072920), a novel $5^{\prime}$ splice donor within exon 11 and a novel $3^{\prime}$ splice acceptor within exon 12 are used such that $103 \mathrm{bp}$ at the $3^{\prime}$ end of exon 11 and $155 \mathrm{bp}$ at the $5^{\prime}$ end of exon 12 are skipped. It should be noted that this splicing event does not correspond to the gt-ag rule (Catterall et al. 1978; here, it is ca-ag). This leads to an internal, in-frame deletion of 86 amino acids (aa 447-533, 


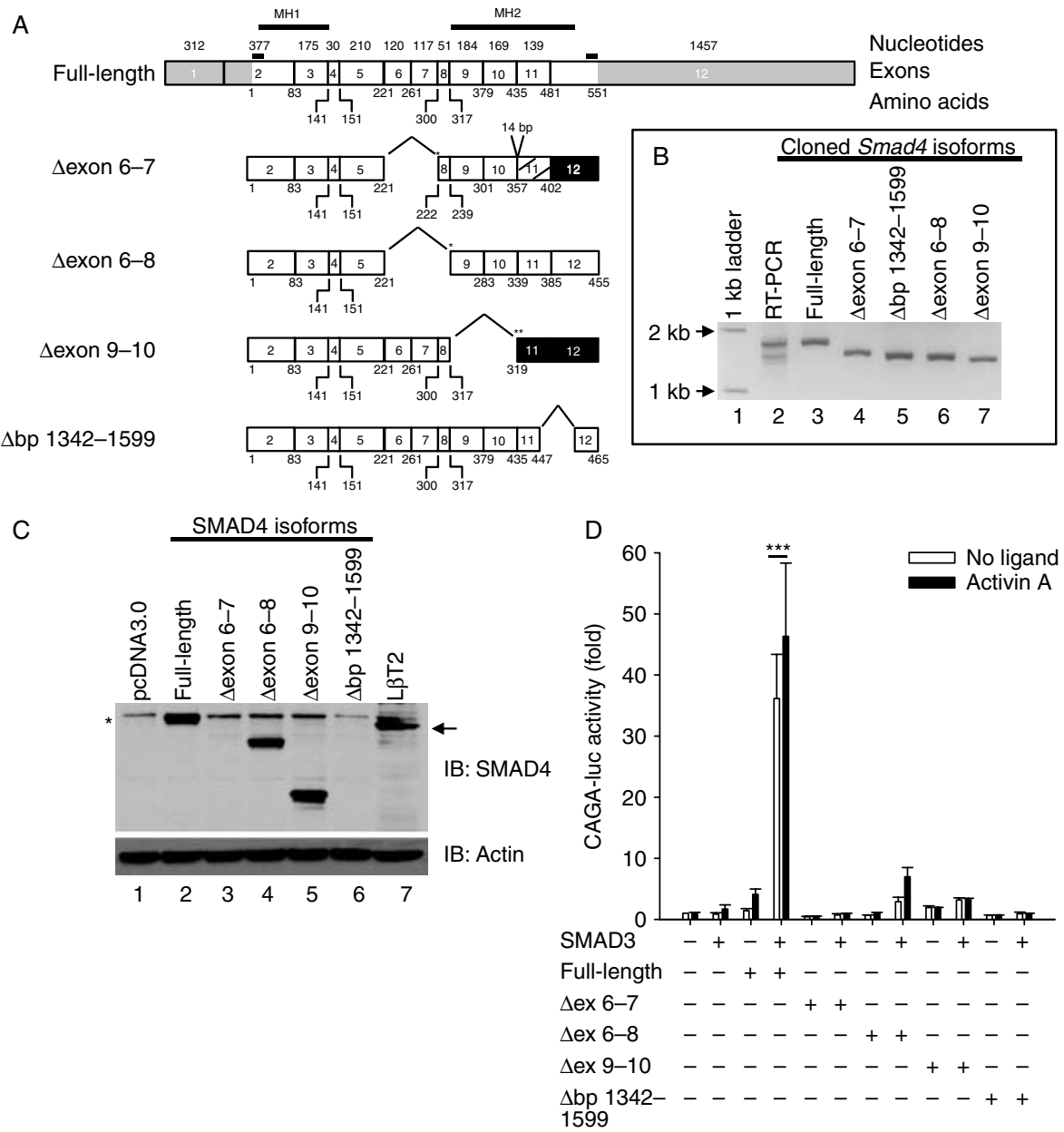

Figure 1 Five Smad4 mRNA isoforms expressed in L $\beta T 2$ cells exhibit different expression and function. (A) Schematic representation of the different Smad4 mRNA isoforms. At the top is the full-length mRNA (based on GenBank accession no. NM_008540), with exons 1-12 labeled from left to right. Shaded and unshaded boxes reflect untranslated and translated sequences respectively. The size of the exons (in bp) is indicated at the top. Amino acids are numbered at the bottom. The relative positions of Mad homology (MH) domains 1 and 2 are indicated at the top of the figure. The short black bars above exons 2 and 12 reflect the relative positions of the PCR primers used in the original RT-PCR analysis. Sequences skipped (relative to the full-length form), as a result of alternative splicing, are indicated with lines. Asterisks denote differences in amino acids from those in the full-length protein, whereas the hatched carboxyl-terminus of the $\Delta$ ex6-7 isoform indicates novel amino acids arising from a frameshift. Blackened exons in two of the variants reflect untranslated sequences resulting from the alternative splicing events. (B) RT-PCR for Smad4 from LßT2 cDNA (lane 2). PCR fragments were TA cloned and sequenced. Inserts from clones representative of the five different Smad4 isoforms identified are shown in lanes 3-7. (C) Immunoblot (IB; $10 \%$ Tris-glycine) of SW480.7 cells transfected with the indicated FLAGtagged expression vectors for the different SMAD4 isoforms. Whole cell extract from L $\beta T 2$ cells was run in lane 7 for comparison. The * and the arrow denote a non-specific band and full-length SMAD4 respectively. (D) Reporter assay (CAGA-luc) results from SW480.7 cells transfected with the indicated SMAD4 constructs in the presence or absence of wild-type SMAD3 and then treated with activin A. Data are plotted relative to the control condition (no SMADs or ligand) set to 1. All treatments were done in triplicate, and the experiment was performed three times. ${ }^{\star * \star}$ The combination of wild-type SMAD4 with SMAD3 was significantly different from all other treatments $(P<0.001)$, which did not differ from one another. 
including 82 amino acids of the MH2 domain) relative to the full-length SMAD4. None of the novel isoforms described here match the sequences currently deposited in the GenBank.

All five isoforms were subcloned into an expression vector such that a FLAG tag was added to the $\mathrm{N}$-terminus of the expressed proteins. Upon transfection into SMAD4-deficient SW480.7 cells (Calonge \& Massague 1999), we observed the expression of the full-length SMAD4 (Fig. 1C, lane 2), SMAD4 $4^{\Delta e x 6-8}$ (lane 4), and SMAD4 $4^{\text {ex9-10 }}$ (lane 5), but did not observe protein expression for SMAD4 ${ }^{\Delta \operatorname{ex6} 6}$ (lane 3) or $\mathrm{SMAD}^{\Delta \mathrm{bp} 1342-1599}$ (lane 6). Similar results were observed when the blot was probed with the FLAG antibody or when the constructs were transfected into CHO cells (data not shown). Northern blot analysis confirmed mRNA expression of all the isoforms in the transfected cells (data not shown), suggesting that the SMAD $4^{\Delta \mathrm{ex} 6-7}$ and $\mathrm{SMAD}^{\Delta \mathrm{bp} 1342-1599}$ proteins are unstable. In western blot analysis of endogenous SMAD4 protein expression in L $\beta$ T2 cells, only one protein was detected, which corresponded to the fulllength form (Fig. 1C, lane 7; note that the slightly different migration in lanes 2 and 7 likely reflects the addition of the FLAG tag to the protein in lane 2). In SW480.7 cells, the full-length SMAD4 potently stimulated the activity of a SMAD3/4-responsive promoterreporter (CAGA-luc) when co-transfected with SMAD3, both in the presence and in the absence of activin A (Fig. 1D). SMAD $4^{\Delta \text { ex6-8 }}$ and SMAD $4^{\Delta \text { ex9-10 }}$ also displayed some activity in this assay, but with much lower efficacy than the full-length SMAD4 and not statistically significantly. Similar results were observed when cells were treated with TGF $\beta 1$ (data not shown). Collectively, these data suggest that the full-length SMAD4 is the most abundant and biologically active isoform of the SMAD4 isoforms identified in L $\beta$ T2 cells.

\section{Intracellular SMAD4 distribution}

In the classical model of activin/TGF $\beta$ signaling, cytosolic SMAD4 binds to receptor-activated SMAD2 and/or SMAD3 prior to accumulation in the nucleus (Massague 1998). More recent data indicate that SMAD4 shuttles between the cytosolic and nuclear compartments even in the absence of ligand-activated signaling (Pierreux et al. 2000). We therefore examined the subcellular distribution of SMAD4 in LBT2 cells under different conditions using confocal immunofluorescence microscopy. In the control cells (serumfree), SMAD4 was localized primarily in the cytoplasm, with a small amount of nuclear staining also being evident (Fig. 2, panel a, and Table 2). Treatment of cells with activin A caused accumulation of SMAD4 in cell nuclei, though SMAD4 was still present in the
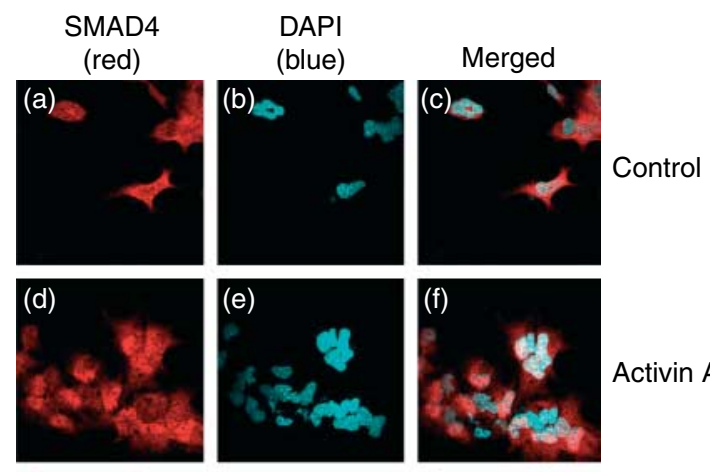

Activin A
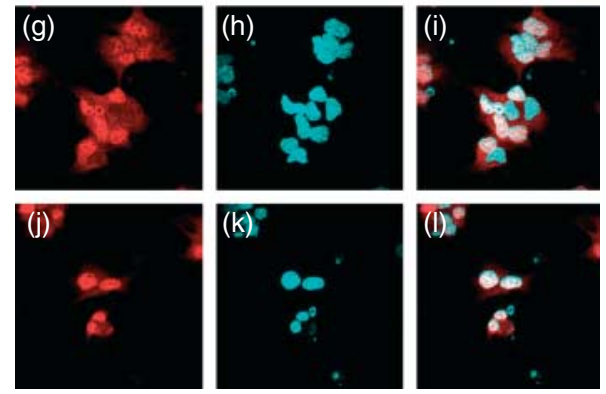

LMB

Figure 2 SMAD4 accumulates in the nuclei of L $\beta T 2$ cells following exogenous activin A treatment. $L \beta T 2$ cells seeded on Matrigelcoated cover slips were untreated $(\mathrm{a}-\mathrm{c})$ or treated with activin $\mathrm{A}$ for $30 \mathrm{~min}(\mathrm{~d}-\mathrm{f})$, LMB for $60 \mathrm{~min}(\mathrm{~g}-\mathrm{i})$, or LMB for $60 \mathrm{~min}$ followed by activin $A$ for an additional $30 \mathrm{~min}(\mathrm{j}-\mathrm{l})$. Cells were stained for SMAD4 by immunofluorescence (red) and visualized by confocal microscopy. Nuclei were counterstained with DAPI (blue).

cytosol (Fig. 2, panel d). Approximately $26-40 \%$ of the cells showed significant nuclear accumulation of SMAD4 following 1-6-h activin A treatment (Table 2). Following treatment with the chromosomal region maintenance 1 inhibitor, LMB, which prevents SMAD4 nuclear export (Pierreux et al. 2000, Watanabe et al. 2000), $>80 \%$ of the cells exhibited SMAD4 nuclear accumulation (Fig. 2, panel g, and Table 2). Similar results were obtained with LMB and activin A co-administration (Fig. 2, panel j). Treatment of cells with SB431542, a small molecule inhibitor of ALK4/5/7 (Inman et al. 2002), to block endogenous or Matrigel-derived activins, did not impair LMB-induced SMAD4 nuclear accumulation (Table 2). Collectively, these data indicate that SMAD4 shuttles in and out of the nucleus in the absence of endogenous activin signaling in L $\beta \mathrm{T} 2$ cells, but that exogenous activin A treatment stimulates increased nuclear SMAD4 accumulation.

\section{Endogenous SMAD4 is required for activin A induction of Fshb}

To demonstrate a functional role for endogenous SMAD4 in activin-regulated $F s h b$ expression, we used siRNAs directed against murine Smad4 mRNA to 
deplete endogenous protein levels. We first tested the efficacy of two commercial Smad4 siRNAs. In our experience, the low transfection efficiency of L $\beta \mathrm{T} 2$ cells precludes an accurate assessment of siRNAmediated knockdown of endogenous mRNAs or proteins in these cells (Bernard 2004, Lamba et al. 2009). Therefore, we customarily use co-transfection of both the siRNA and its target to assess knockdown efficiency. Here, we co-transfected L $\beta$ T2 cells with a wild-type (WT) full-length murine FLAG-SMAD4 expression vector along with different siRNAs. Anti-FLAG western blots confirmed the expression of FLAG-SMAD4 (Fig. 3A, lane 3), which was inhibited by co-transfected Smad4 siRNA \#2 (lane 6), but not by the control (lane 4) or Smad4 \#1 siRNAs (lane 5). Using another murine cell line, NIH3T3, we demonstrated a similar efficacy of the siRNAs on the endogenous target (data not shown). In subsequent analyses, we used both Smad4 siRNAs, with \#1 serving as an additional negative control, given its apparent inability to suppress SMAD4 expression. It should be noted that Smad4 siRNA \#2 is directed against a sequence encoded by exon 7 , and therefore, would not affect the expression of the SMAD $4^{\Delta \operatorname{ex6} 6}$ or SMAD $4^{\mathrm{Aex6-8}}$ isoforms.

Smad4 siRNA \#2, but neither the control nor Smad4 siRNA \#1, inhibited basal and activin A-induced murine Fshb promoter-reporter activity (Fig. 3B). Similar results were observed with a porcine $F$ shb reporter (Fig. 3C). In contrast, neither Smad4 siRNA affected GNRH1stimulated human $L H B$ promoter-reporter activity (Fig. 3D), a SMAD-independent response (Fortin et al. 2009). To determine whether these observations extended to the regulation of the endogenous $F s h b$ gene, we co-transfected L $\beta$ T2 cells with a constitutively active form of the activin type I receptor, ALK4-T206D (TD; Attisano et al. 1996), and the control or Smad4\#2 siRNA. As reported previously, ALK4TD potently stimulated Fshb mRNA levels (Bernard 2004, Lamba et al. 2009). This effect was significantly inhibited by the Smad4 siRNA (Fig. 3E). Comparable results were observed with the murine $F s h b$ promoter-reporter (Fig. 3F). Collectively, these data demonstrate a necessary role for endogenous SMAD4 in activin A/ALK4 induction of murine $F s h b$ transcription.

\section{SMAD4 must bind to DNA to mediate activin $A$ induction of the Fshb promoter}

As an additional control for the siRNA studies, we performed 'rescue' experiments. Here, we introduced bp changes in the full-length SMAD4 expression vector, which prevented siRNA-mediated knockdown, but preserved the amino acid sequence. The WT and siRNA-resistant (Res.) forms of SMAD4 were expressed at equivalent levels in L $\beta \mathrm{T} 2$ cells (Fig. 4A, lanes 2 and 3). Whereas WT SMAD4 was significantly knocked down by Smad4 siRNA \#2 (lane 5), siRNA-resistant SMAD4 was not (lane 6). These data demonstrated the sequence specificity of the siRNA effect on SMAD4 expression. Next, siRNA-resistant SMAD4 was co-transfected with the murine $F$ shb-luc reporter and Smad4 siRNA \#2 into LBT2 cells, which were then treated with activin A for $6 \mathrm{~h}$. The Smad4 siRNA once again abolished the activin A response (Fig. 4B). Here, the siRNA-resistant SMAD4 rescued the activin A effect without significantly altering basal activity (Fig. 4B).

We next examined specific features of SMAD4 required for its activity. We showed that SMAD4 can bind to the consensus SBE from the murine $F s h b$ promoter in vitro in an activin-regulated fashion (Lamba et al. 2006). To determine whether or not SMAD4 must bind directly to DNA to mediate the activin response, we repeated the siRNA knockdown and rescue approach using an siRNA-resistant form of SMAD4 harboring a missense mutation, K88R, which was shown previously to prevent direct DNA binding (Moren et al. 2000). SMAD4-K88R was expressed at high levels in L $\beta \mathrm{T} 2$ cells, whether in an siRNA-sensitive or siRNA-resistant form (Fig. 4C, lanes 2 and 3). As with the WT constructs, the siRNA-sensitive, but not siRNAresistant, form of K88R was significantly depleted in cells co-transfected with the Smad4 siRNA (Fig. 4C, lanes 5 and 6). Unlike the siRNA-resistant WT SMAD4, which potently rescued activin A induction of Fshb-luc activity, the siRNA-resistant K88R mutant was completely incapable of rescuing the activin response (Fig. 4D). These data suggest that SMAD4 must bind to DNA directly to mediate activin A induction of the murine $F s h b$ promoter.

\section{Constitutively nuclear SMAD4 can mediate activin A induction of Fshb}

To assess whether cytosolic to nuclear shuttling of SMAD4 is required for activin A induction of the Fshb gene or whether SMAD4 resident in the nucleus is sufficient to broker the activin A response, we first transfected L $\beta$ T2 cells with the murine $F s h b$ promoterreporter, and then treated them with LMB for $60 \mathrm{~min}$ prior to activin A treatment for an additional $6 \mathrm{~h}$. LMB attenuated, but did not completely block, activin A induction of promoter activity (Fig. 5A). Similarly, 2-h activin A treatment stimulated a marked increase in endogenous Fshb mRNA levels, and this effect was attenuated, but not blocked by $30-\mathrm{min}$ LMB pre-treatment (Fig. 5B, compare lane 2 and lane 4). It is possible that the residual activin A effect depended on de novo synthesized SMAD4 prior to its accumulation in the nucleus and retention by 


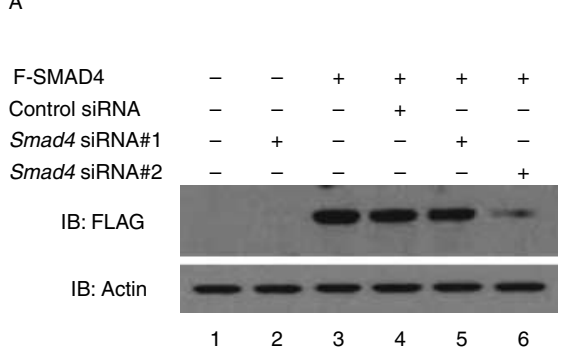

C
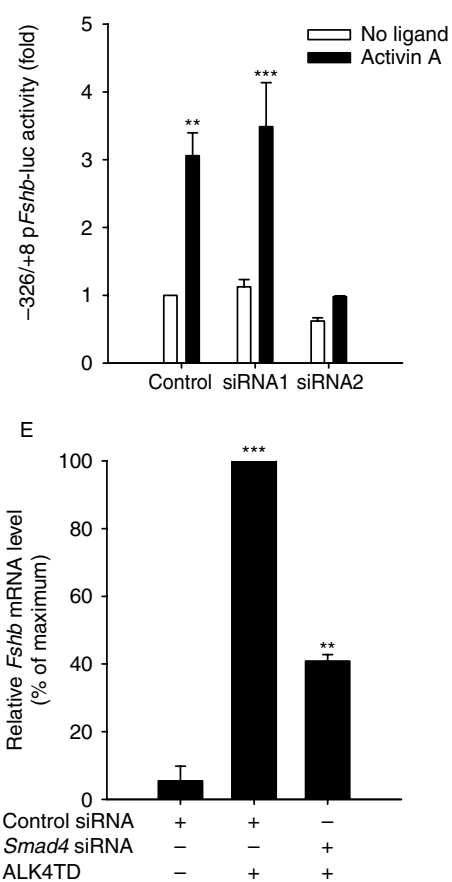
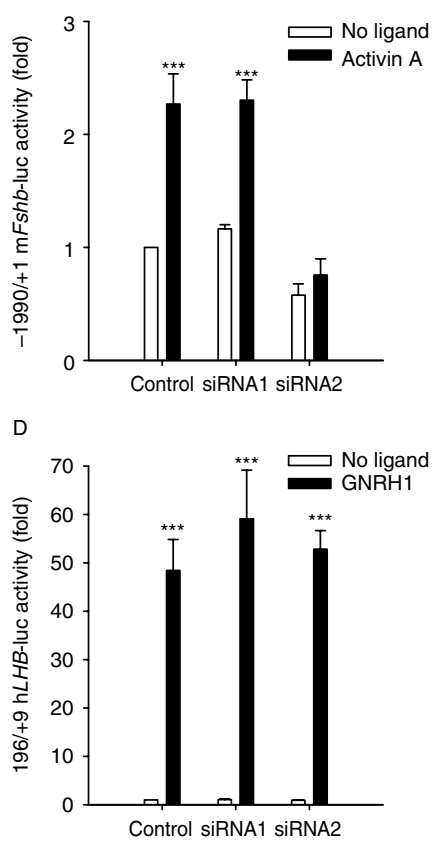

$\mathrm{F}$

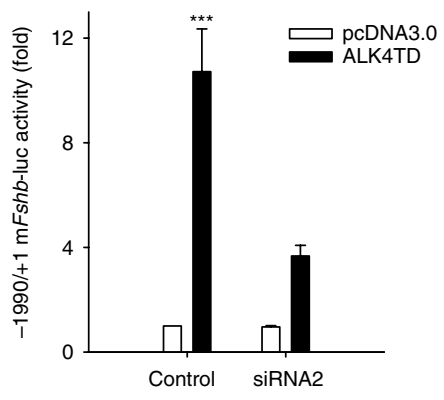

Figure 3 SMAD4 knockdown abrogates activin A induction of Fshb transcription.

(A) Immunoblot of whole cell extracts of L $\beta T 2$ cells co-transfected with FLAG(F)-SMAD4 and the indicated siRNAs $(5 \mathrm{nmol} / \mathrm{I})$. Over-expressed SMAD4 was detected with a FLAG antibody, and $\beta$-actin was used as a loading control. (B) L $\beta$ T2 cells were co-transfected with a murine Fshb promoter-reporter and the indicated siRNAs $(5 \mathrm{nmol} / \mathrm{l})$. The cells were then treated with $1 \mathrm{nmol} / \mathrm{l}$ activin A for $6 \mathrm{~h}$ prior to luciferase assays. All treatments were done in triplicate, and the experiment was performed three times. ${ }^{\star \star \star}$ Significantly different from the control siRNA/no ligand condition $(P<0 \cdot 001)$. (C) Cells were transfected as in B, but with a porcine Fshb promoter-reporter. All treatments were done in triplicate, and the experiment was performed three times. Significant differences from the control siRNA/no ligand condition are indicated with asterisks $\left({ }^{* * \star} P<0.001\right.$; ${ }^{\star \star} P<0 \cdot 01$ ). (D) Cells were transfected as in $\mathrm{B}$, but with a human $L H B$-luciferase reporter, and were treated with $100 \mathrm{nmol} / \mathrm{GNRH} 1$ for $6 \mathrm{~h}$. All treatments were done in triplicate, and the experiment was performed three times. ${ }^{* *}$ Significantly different from the control siRNA/no ligand condition $(P<0 \cdot 001)$. (E) L $\beta T 2$ cells were co-transfected with a constitutively active form of the activin type I receptor, ALK4TD, and control or Smad4 siRNA. RNA was extracted and Fshb mRNA was measured by qRT-PCR. Data are plotted relative to ALK4TD with control siRNA set to $100 \%$. The data are from two independent experiments. Significant differences from the control siRNA/no ALK4TD condition are indicated with asterisks $\left({ }^{\star \star \star} P<0.001 ;{ }^{* \star} P=0.002\right)$. (F) L $\beta T 2$ cells were co-transfected with a murine Fshb promoter-reporter and the indicated siRNAs in combination with empty vector (pcDNA3) or ALK4TD expression vector. All treatments were done in triplicate, and the experiment was performed four times. ${ }^{* \star}$ Significantly different from the control siRNA/pcDNA3.0 condition $(P<0.001)$. 


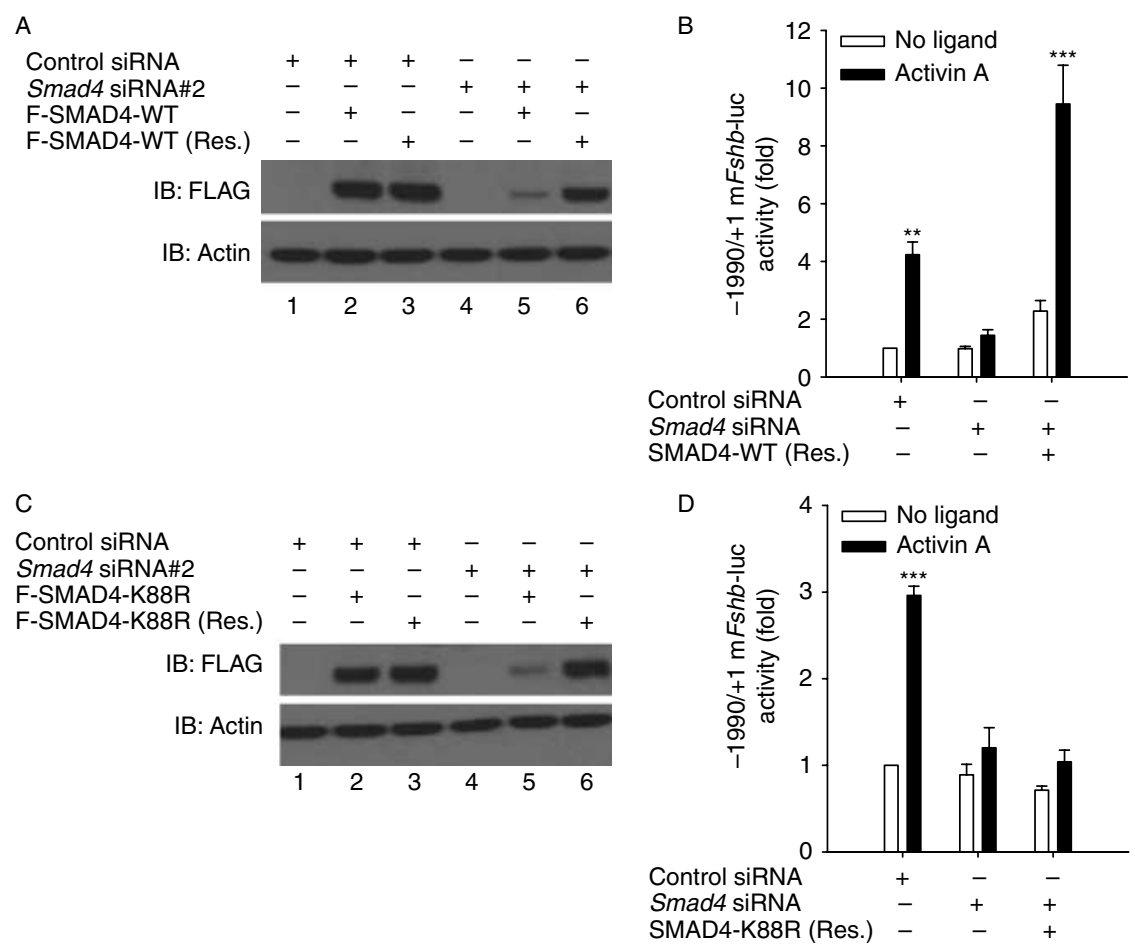

Figure 4 The effect of SMAD4 depletion is rescued by wild-type SMAD4, but not by DNA-binding-deficient SMAD4. (A) Immunoblot of whole cell extracts of L $\beta$ T2 cells co-transfected with wild-type (WT) or siRNA-resistant (Res.) FLAG(F)-SMAD4 and the indicated siRNAs $(5 \mathrm{nmol} / \mathrm{l})$. Over-expressed SMAD4 was detected with a FLAG antibody, and $\beta$-actin was used as a loading control. For the siRNA-resistant SMAD4, the nucleotide sequence targeted by the siRNA was modified without changing the amino acid sequence. (B) L $\beta$ T2 cells were co-transfected with a murine Fshb promoterreporter, $20 \mathrm{ng} /$ well of pcDNA3.0 $(-)$ or siRNA-resistant SMAD4 $(+)$, and the indicated siRNAs $(5 \mathrm{nmol} / \mathrm{l})$. The cells were then treated with $1 \mathrm{nmol} / \mathrm{l}$ activin $A$ for $6 \mathrm{~h}$ prior to luciferase assays. All treatments were done in triplicate, and the experiment was performed five times. Asterisks denote significant differences from the control siRNA/no ligand condition $\left({ }^{* *} P<0 \cdot 01 ;{ }^{* \star *} P<0 \cdot 001\right)$. (C and D) Cells were transfected and treated as in A and B, except that a DNA-binding-deficient form of SMAD4 (K88R) was used in place of wild-type SMAD4 here. In D, all treatments were done in triplicate, and the experiment was performed three times. ${ }^{* *}$ Significantly different from the control siRNA/no ligand condition $(P<0.001)$.

LMB. To address this possibility, we pretreated cells with the translation inhibitor CHX. We reported previously that murine $F s h b$ is an activin immediateearly response gene (Bernard 2004), and we once again observed that CHX alone did not affect activin A-stimulated Fshb mRNA levels here (Fig. 5B, compare lane 2 and lane 3). Activin A induction of Fshb mRNA was similar in the presence of LMB alone or in combination with CHX (compare lane 4 and lane 5), suggesting that de novo SMAD4 synthesis did not account for the residual activin A response in the presence of LMB.

Treatment of cells with LMB did not lead to the complete redistribution of SMAD4 in the nucleus, at least not in the time frame used here (Fig. 2). Therefore, it is possible that the remaining cytosolic
SMAD4 mediated the activin A effect on Fshb. To determine whether exclusively nuclear SMAD4 was sufficient, we again depleted endogenous SMAD4 levels with siRNA \#2. We then performed a rescue experiment with an siRNA-resistant form of SMAD4 that localizes exclusively to the nucleus. It was reported previously that leucine to alanine mutations at positions 146 and 148 (within the nuclear export signal) of SMAD4 lead to its exclusive nuclear distribution (Pierreux et al. 2000). We confirmed this observation in transfected L $\beta$ T2 cells (Fig. 5C). When co-expressed with SMAD3, SMAD $4^{\mathrm{L} 146 / 148 \mathrm{~A}}$ synergistically stimulated Fshb promoter activity, though it did so slightly less effectively than WT SMAD4 (Fig. 5D, $P=0 \cdot 002$ versus $P<0 \cdot 001$ ). Importantly, SMAD $4^{\mathrm{L} 146 / 148 \mathrm{~A}}$ also rescued the activin A response in SMAD4-depleted cells (Fig. 5E). 
A

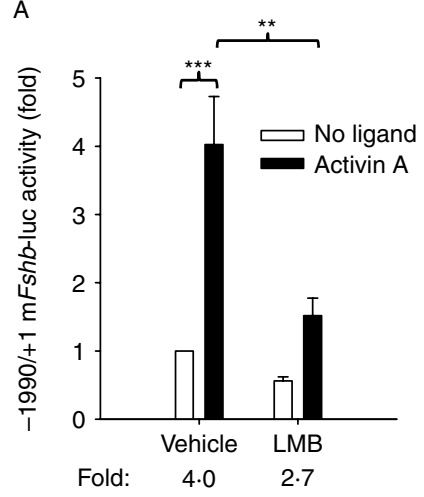

C
B

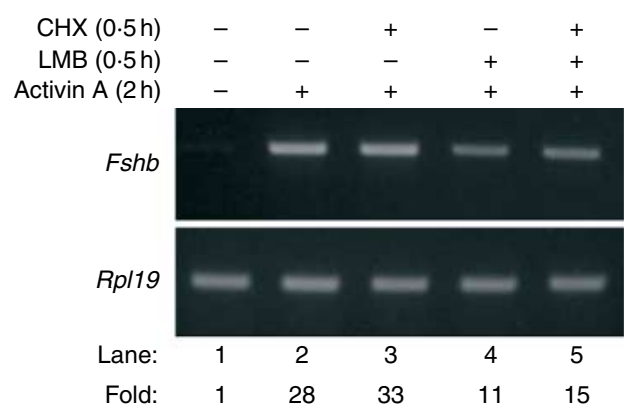

DAPI

(blue)
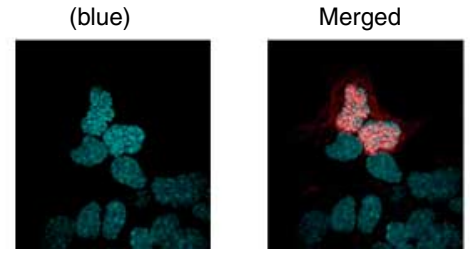

E

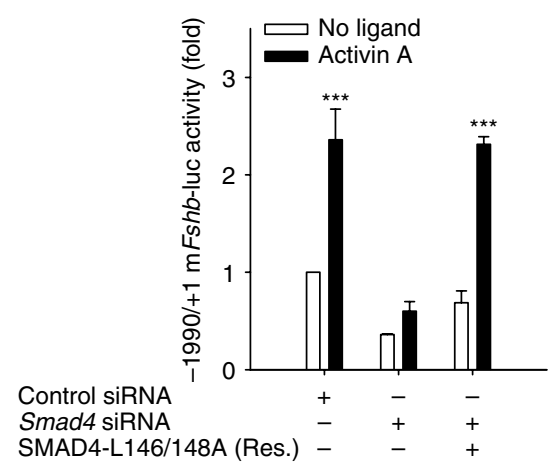

Figure 5 Constitutively nuclear SMAD4 can mediate activin induction of Fshb transcription. (A) L $\beta T 2$ cells were transfected with a murine Fshb promoter-reporter. The cells were then treated with a vehicle (0.01\% ethanol) or $2 \mathrm{ng} / \mathrm{ml} \mathrm{LMB}$ for $30 \mathrm{~min}$ followed by 6 -h treatment with $1 \mathrm{nmol} / \mathrm{l}$ activin A prior to luciferase assays. All treatments were done in triplicate, and the experiment was performed three times. ${ }^{* *}$ Significantly different from the LMB/activin A condition $(P<0.002)$. ${ }^{* \star}$ Significantly different from the vehicle/no ligand condition $(P<0.001)$. (B) L $\beta$ T2 cells seeded in six-well plates were treated with $\mathrm{LMB}(2 \mathrm{ng} / \mathrm{ml})$ and/or $\mathrm{CHX}(5 \mu \mathrm{g} / \mathrm{ml}) 30 \mathrm{~min}$ prior to treatment with $1 \mathrm{nmol} / \mathrm{l}$ activin $\mathrm{A}$ for $2 \mathrm{~h}$. RNA was extracted, and Fshb mRNA levels were analyzed by semi-quantitative RT-PCR. Rp/19 was used as a loading control. The same samples were then analyzed by quantitative RT-PCR; the fold induction by activin $A$ is indicated below each lane. (C) $L \beta T 2$ cells seeded on Matrigelcoated cover slips were transfected with FLAG-SMAD4-L146/148A. The mutant SMAD4 protein (red, anti-FLAG) was localized by confocal microscopy. (D) L $\beta T 2$ cells were co-transfected with the murine Fshb reporter and the indicated combinations of WT SMAD4 or L146/148A SMAD4 along with WT SMAD3. The data are from three independent experiments, with each treatment being performed six times. Asterisks denote significant differences from the pcDNA3.0/pcDNA3.0 condition ( $\left.{ }^{\star \star \star} P<0.001\right)$. (E) L $\beta T 2$ cells were co-transfected with the murine Fshb promoter-reporter, $20 \mathrm{ng} /$ well of pcDNA3.0 ( - ) or siRNA-resistant SMAD4-L146/148A ( + ), and the indicated siRNAs $(5 \mathrm{nmol} / \mathrm{l})$. The cells were then treated with $1 \mathrm{nmol} / \mathrm{l}$ activin A for $6 \mathrm{~h}$ prior to luciferase assays. All treatments were done in triplicate, and the experiment was performed three times. ${ }^{\star \star \star}$ Significantly different from the control siRNA/no ligand condition $(P<0.001)$. 
Collectively, these data demonstrate that constitutively nuclear SMAD4 was sufficient to broker activin A induction of the murine Fshb transcription.

\section{Discussion}

Over the past few years, we and others have investigated the mechanisms mediating activin induction of FSH $\beta$ $(F s h b)$ subunit gene transcription in rodents. Here, we extend our understanding of these mechanisms by making the following observations: 1) L $\beta T 2$ cells express at least five Smad4 mRNA isoforms; 2) SMAD4 shuttles in and out of the nucleus in the absence of ligand in these cells, but activin A stimulates its nuclear accumulation; 3) depletion of endogenous SMAD4 by RNAi abrogates activin A-induced Fs $h b$ subunit transcription; 4) SMAD4 must bind to DNA to mediate activin A induction of the $F s h b$ promoter; and 5) constitutively nuclear SMAD4 can broker activin A induction of Fshb transcription.

Our analysis revealed the presence of four novel Smad4 mRNA splice variants in L $\beta$ T2 cells; only two of which (SMAD4 $4^{\Delta \text { ex6-8 }}$ and SMAD4 $4^{\Delta \operatorname{ex} 9-10}$ ) were detected at the protein level when expressed in heterologous cells. Both show some activity in functional assays, but only at a fraction of the level observed with the fulllength SMAD4. SMAD $4^{\Delta \text { ex9-10 }}$ lacks the entirety of the MH2 domain, which mediates its homo- and heterooligomerization (Shi et al. 1997, Chacko et al. 2004). This might explain its limited functionality in inducing CAGA-luc reporter activity. SMAD $4^{\Delta \operatorname{ex} 6-8}$ lacks 96 internal amino acids, corresponding to the C-terminus of the linker domain. The molecular basis for its impaired functionality is unknown, but the data are consistent with a previous report showing that the amino acids encoded by exons $6-8$ are critical for SMAD4 transcriptional activity (Pierreux et al. 2000). This sub-domain may be required for the interaction with co-activators, such as p300 (de Caestecker et al. 2000). We were unable to detect the SMAD $4^{\Delta \operatorname{ex6-7}}$ and SMAD4 $4^{\Delta \mathrm{bp} 1342-1599}$ proteins when expressed in heterologous cells. Because we could measure mRNA for both isoforms in both LBT2 and transfected cells, the data suggest that these protein isoforms are unstable. A human SMAD4 mutant, which lacks the C-terminal 38 amino acids of the protein, is similarly unstable and is degraded through the ubiquitin-proteasome pathway (Maurice et al. 2001). Collectively, the data show that L $\beta$ T2 cells express multiple Smad4 mRNA isoforms, but through either relative mRNA expression levels, differences in trans-activation function, or protein stability, only the full-length form is likely to have a physiological role in $F s h b$ transcription. Indeed, this is borne out in the siRNA-rescue paradigm, wherein full-length SMAD4 is sufficient to fully restore activin-induced promoter activity. It will be important to determine whether similar and/or additional Smad4 isoforms are expressed in adult gonadotropes in vivo.

We have observed that SMAD4 shuttles in and out of the nucleus in a ligand-independent fashion in L $\beta$ T2 cells as described in other cell types (Pierreux et al. 2000). Under basal conditions, SMAD4 is predominantly cytosolic. Recent data indicate that SMAD4 subcellular localization is controlled, at least in part, by its monoubiquitination at lysine 519 . Ubiquitination is associated with SMAD4 nuclear export, whereas cytosolic de-ubiquitination (by USP9x) is required for ligand-induced nuclear accumulation (Dupont et al. 2009). If the same mechanisms apply in L $\beta T 2$ cells, our data suggest that under basal conditions, SMAD4 is likely to be in a predominantly monoubiquitinated state. After activin A treatment, we observed SMAD4 accumulation in $\sim 30-40 \%$ of the cells, and this pattern is relatively stable for 1-6 h. In contrast, $90 \mathrm{~min}$ of LMB treatment is sufficient to promote SMAD4 nuclear accumulation in $>80 \%$ of the cells. Together, these data suggest that not all L $\beta$ T2 cells are equally responsive to activin $\mathrm{A}$ at any given time. Further work, with real-time imaging, is needed to determine whether the same cells show persistent nuclear SMAD4 for $6 \mathrm{~h}$ or whether there are cycles of activin A responsiveness in different cell populations. It will also be important to determine whether increases in Fshb expression are preferentially or exclusively observed in those cells in which SMAD4 accumulates in the nucleus.

Previous work by us and others strongly suggested a role for SMAD4 in activin induction of Fshb transcription; however, the earlier data were derived entirely from over-expression analyses (Suszko et al. 2003, Bernard 2004, Gregory et al. 2005, Lamba et al. 2006). Here, we definitively established a necessary role for endogenous SMAD4 in activin A induction of both murine and porcine $F s h b$ promoter-reporters by knocking down SMAD4 expression in L $\beta \mathrm{T} 2$ cells using RNAi. We further demonstrated the specificity of the knockdown effect through our ability to rescue the activin A effect with an siRNA-resistant SMAD4 expression vector. In previous work, we and others similarly knocked down SMAD2 or SMAD3 expression, and observed significant attenuation of activin-induced Fshb transcription (Bernard 2004, Suszko et al. 2005, Lamba et al. 2006, 2009). However, unlike the case with SMAD4 here, we never achieved complete abrogation of the response. We speculated previously that there may be some functional redundancy between SMAD2 and SMAD3 that might explain these results. Here, the data clearly show that no proteins can compensate for the loss of SMAD4.

Using in vitro binding assays, such as gel shifts and DNA affinity pull-downs, we and others demonstrated previously activin A-stimulated association of SMAD2, 
SMAD3, and SMAD4 with a conserved SBE in the proximal murine and rat promoters (Suszko et al. 2003, Gregory et al. 2005, Lamba et al. 2006). Importantly, one report confirmed activin A-induced SMAD4 recruitment to the proximal murine $F s h b$ promoter in L $\beta \mathrm{T} 2$ cells by chromatin immunoprecipitation (Melamed et al. 2006). Mutation of the SBE attenuates both activin A and SMAD2/3/4 induction of promoter-reporter activity (Suszko et al. 2003, Gregory et al. 2005, Lamba et al. 2006, McGillivray et al. 2007). Though these data clearly demonstrate the importance of the SBE for SMAD action and the ability of activins to stimulate SMAD4 recruitment to this part of the Fshb promoter, they do not definitively establish a necessary role for direct DNA binding by SMAD4. Here, however, we have clearly shown that SMAD4 DNA-binding activity is fundamentally required for activin A induction of murine $F s h b$ transcription. In the context of the SMAD4 knockdown paradigm, a SMAD4 point mutant (K88R) with abrogated DNA-binding activity (Moren et al. 2000) is incapable of rescuing activin induction of promoter activity. These data are consistent with our previous observation that WT SMAD4, but not SMAD4-K88R, can rescue the stimulatory effects of a DNA-bindingdeficient form of SMAD3 (R74K; Lamba et al. 2006). Collectively, the data suggest that SMAD4 DNA-binding activity is required for activin-induced Fs $h b$ expression.

Though SMAD2 and SMAD3 are classically described to partner with SMAD4 in the cytosol prior to nuclear translocation, previous reports demonstrate near WT functionality of constitutively nuclear forms of SMAD4 (Pierreux et al. 2000, Biondi et al. 2007). We have observed similar results in L $\beta$ T2 cells. That is, blocking of SMAD4 nuclear export with LMB attenuates, but does not block, activin A induction of $F s h b$ mRNA expression or promoter-reporter activity. Similarly, a constitutively nuclear form of SMAD4 can broker activin A induction of $F s h b$ transcription in SMAD4-depleted cells, with nearly WT efficacy. Because SMAD4 exhibits ligand-independent nucleocytoplasmic shuttling, these observations suggest that activin A-stimulated (phosphorylated) SMAD2/3 can partner with SMAD4 in the cytosol and/or nucleus to regulate $F s h b$ promoter activity. These observations may help explain how mice engineered to express constitutively nuclear SMAD4 remain fertile (and presumably have normal FSH levels; Biondi et al. 2007).

In summary, the data presented here and previously suggest a model in which SMAD4 shuttles in and out of the nucleus of gonadotropes. Upon activin exposure, SMAD2 and SMAD3 are phosphorylated and partner with SMAD4 in the cytosol or nucleus and form complexes that accumulate in the nucleus over time. These complexes, via SMAD3 and SMAD4, bind to the proximal Fs $h b$ promoter through an 8-bp SBE and other elements (McGillivray et al. 2007, Lamba et al. 2009) to drive transcription.

\section{Declaration of interest}

The authors declare that there are no conflicts of interest that could be perceived as prejudicing the impartiality of the research reported.

\section{Funding}

This work was supported by the Canadian Institutes of Health Research (grant no. MOP-89991). D J Bernard is a Chercheur-boursier of the fonds de recherche en santé du Québec.

\section{Acknowledgements}

The authors thank Dr Stephane Laporte and Eugénie Goupil for the use of the confocal microscope and technical assistance respectively. Jérôme Fortin and Dr Pankaj Lamba provided valuable feedback on an earlier draft of the manuscript. The authors also thank several investigators for providing valuable reagents (as indicated in the text).

\section{References}

Alarid ET, Windle JJ, Whyte DB \& Mellon PL 1996 Immortalization of pituitary cells at discrete stages of development by directed oncogenesis in transgenic mice. Development 122 3319-3329.

Attardi B \& Miklos J 1990 Rapid stimulatory effect of activin-A on messenger RNA encoding the follicle-stimulating hormone beta-subunit in rat pituitary cell cultures. Molecular Endocrinology 4 721-726.

Attisano L, Wrana JL, Montalvo E \& Massague J 1996 Activation of signalling by the activin receptor complex. Molecular and Cellular Biology 16 1066-1073.

Bergeron D, Barbeau B, Leger C \& Rassart E 1995 Experimental bias in the evaluation of the cellular transient expression in DNA co-transfection experiments. Cellular and Molecular Biology Research 41 155-159.

Bernard DJ 2004 Both SMAD2 and SMAD3 mediate activin-stimulated expression of the follicle-stimulating hormone beta subunit in mouse gonadotrope cells. Molecular Endocrinology 18 606-623.

Biondi CA, Das D, Howell M, Islam A, Bikoff EK, Hill CS \& Robertson EJ 2007 Mice develop normally in the absence of Smad4 nucleocytoplasmic shuttling. Biochemical Journal 404 235-245.

de Caestecker MP, Yahata T, Wang D, Parks WT, Huang S, Hill CS, Shioda T, Roberts AB \& Lechleider RJ 2000 The Smad4 activation domain (SAD) is a proline-rich, p300-dependent transcriptional activation domain. Journal of Biological Chemistry 275 2115-2122.

Calonge MJ \& Massague J 1999 Smad4/DPC4 silencing and hyperactive Ras jointly disrupt transforming growth factor-beta antiproliferative responses in colon cancer cells. Journal of Biological Chemistry 274 33637-33643.

Catterall JF, O'Malley BW, Robertson MA, Staden R, Tanaka Y \& Brownlee GG 1978 Nucleotide sequence homology at 12 intronexon junctions in the chick ovalbumin gene. Nature 275 510-513.

Chacko BM, Qin BY, Tiwari A, Shi G, Lam S, Hayward LJ, De Caestecker M \& Lin K 2004 Structural basis of heteromeric smad protein assembly in TGF-beta signaling. Molecular Cell 15 813-823.

Dennler S, Itoh S, Vivien D, ten Dijke P, Huet S \& Gauthier JM 1998 Direct binding of Smad3 and Smad4 to critical TGF beta-inducible elements in the promoter of human plasminogen activator inhibitor-type 1 gene. EMBO Journal 17 3091-3100.

Dupont S, Mamidi A, Cordenonsi M, Montagner M, Zacchigna L, Adorno M, Martello G, Stinchfield MJ, Soligo S, Morsut L et al. 2009 FAM/USP9x, a deubiquitinating enzyme essential for TGFbeta signaling, controls Smad4 monoubiquitination. Cell 136 123-135. 
Fortin J, Lamba P, Wang Y \& Bernard DJ 2009 Conservation of mechanisms mediating gonadotrophin-releasing hormone 1 stimulation of human luteinizing hormone beta subunit transcription. Molecular Human Reproduction 15 77-87.

Goyette MC, Cho K, Fasching CL, Levy DB, Kinzler KW, Paraskeva C, Vogelstein B \& Stanbridge EJ 1992 Progression of colorectal cancer is associated with multiple tumor suppressor gene defects but inhibition of tumorigenicity is accomplished by correction of any single defect via chromosome transfer. Molecular and Cellular Biology 12 1387-1395.

Gregory SJ, Lacza CT, Detz AA, Xu S, Petrillo LA \& Kaiser UB 2005 Synergy between activin A and gonadotropin-releasing hormone in transcriptional activation of the rat follicle-stimulating hormonebeta gene. Molecular Endocrinology 19 237-254.

Howcroft TK, Kirshner SL \& Singer DS 1997 Measure of transient transfection efficiency using beta-galactosidase protein. Analytical Biochemistry 244 22-27.

Huszar T, Mucsi I, Terebessy T, Masszi A, Adamko S, Jeney C \& Rosivall L 2001 The use of a second reporter plasmid as an internal standard to normalize luciferase activity in transient transfection experiments may lead to a systematic error. Journal of Biotechnology 88 251-258.

Inman GJ, Nicolas FJ, Callahan JF, Harling JD, Gaster LM, Reith AD, Laping NJ \& Hill CS 2002 SB-431542 is a potent and specific inhibitor of transforming growth factor-beta superfamily type I activin receptor-like kinase (ALK) receptors ALK4, ALK5, and ALK7. Molecular Pharmacology 62 65-74.

Jainchill JL, Aaronson SA \& Todaro GJ 1969 Murine sarcoma and leukemia viruses: assay using clonal lines of contact-inhibited mouse cells. Journal of Virology 4 549-553.

Kageyama H, Seki N, Yamada S, Sakiyama S \& Nakagawara A 1998 DPC4 splice variants in neuroblastoma. Cancer Letters 122 187-193.

Lamba P, Santos MM, Philips DP \& Bernard DJ 2006 Acute regulation of murine follicle-stimulating hormone beta subunit transcription by activin A. Journal of Molecular Endocrinology 36 201-220.

Lamba P, Fortin J, Tran S, Wang Y \& Bernard DJ 2009 A novel role for the forkhead transcription factor FOXL2 in activin A-regulated follicle-stimulating hormone beta subunit transcription. Molecular Endocrinology 23 1001-1013.

Lee KB, Khivansara V, Santos MM, Lamba P, Yuen T, Sealfon SC \& Bernard DJ 2007 Bone morphogenetic protein 2 and activin A synergistically stimulate follicle-stimulating hormone beta subunit transcription. Journal of Molecular Endocrinology 38 315-330.

Ling N, Ying SY, Ueno N, Shimasaki S, Esch F, Hotta M \& Guillemin R $1986 a \mathrm{~A}$ homodimer of the beta-subunits of inhibin A stimulates the secretion of pituitary follicle stimulating hormone. Biochemical and Biophysical Research Communications 138 1129-1137.

Ling N, Ying SY, Ueno N, Shimasaki S, Esch F, Hotta M \& Guillemin R $1986 b$ Pituitary FSH is released by a heterodimer of the beta-subunits from the two forms of inhibin. Nature 321 779-782.

Massague J 1998 TGF- $\beta$ signal transduction. Annual Reviews of Biochemistry 67 753-791.

Matzuk MM, Kumar TR \& Bradley A 1995 Different phenotypes for mice deficient in either activins or activin receptor type II. Nature 374 356-360.

Maurice D, Pierreux CE, Howell M, Wilentz RE, Owen MJ \& Hill CS 2001 Loss of Smad4 function in pancreatic tumors: C-terminal truncation leads to decreased stability. Journal of Biological Chemistry 276 43175-43181.

McGillivray SM, Thackray VG, Coss D \& Mellon PL 2007 Activin and glucocorticoids synergistically activate follicle-stimulating hormone beta-subunit gene expression in the immortalized LbetaT2 gonadotrope cell line. Endocrinology 148 762-773.
Melamed P, Kadir MN, Wijeweera A \& Seah S 2006 Transcription of gonadotropin beta subunit genes involves cross-talk between the transcription factors and co-regulators that mediate actions of the regulatory hormones. Molecular and Cellular Endocrinology 252 167-183.

Moren A, Itoh S, Moustakas A, Dijke P \& Heldin CH 2000 Functional consequences of tumorigenic missense mutations in the amino-terminal domain of Smad4. Oncogene 19 4396-4404.

Pernasetti F, Vasilyev VV, Rosenberg SB, Bailey JS, Huang HJ, Miller WL \& Mellon PL 2001 Cell-specific transcriptional regulation of follicle-stimulating hormone-beta by activin and gonadotropinreleasing hormone in the LbetaT2 pituitary gonadotrope cell model. Endocrinology 142 2284-2295.

Pierreux CE, Nicolas FJ \& Hill CS 2000 Transforming growth factor beta-independent shuttling of Smad4 between the cytoplasm and nucleus. Molecular and Cellular Biology 20 9041-9054.

Puck TT, Cieciura SJ \& Robinson A 1958 Genetics of somatic mammalian cells. III. Long-term cultivation of euploid cells from human and animal subjects. Journal of Experimental Medicine 108 945-956.

Shi Y, Hata A, Lo RS, Massague J \& Pavletich NP 1997 A structural basis for mutational inactivation of the tumour suppressor Smad4. Nature 388 87-93.

Shifera AS \& Hardin JA 2010 Factors modulating expression of Renilla luciferase from control plasmids used in luciferase reporter gene assays. Analytical Biochemistry 396 167-172.

Siedow A, Gratchev A \& Hanski C 2000 Correct evaluation of reporter assays in different cell lines by direct determination of the introduced plasmid amount. European Journal of Cell Biology 79 $150-153$.

Suszko MI, Lo DJ, Suh H, Camper SA \& Woodruff TK 2003 Regulation of the rat follicle-stimulating hormone beta-subunit promoter by activin. Molecular Endocrinology 17 318-332.

Suszko MI, Balkin DM, Chen Y \& Woodruff TK 2005 Smad3 mediates activin-induced transcription of follicle-stimulating hormone beta-subunit gene. Molecular Endocrinology 19 1849-1858.

Thackray VG, McGillivray SM \& Mellon PL 2006 Androgens, progestins, and glucocorticoids induce follicle-stimulating hormone beta-subunit gene expression at the level of the gonadotrope. Molecular Endocrinology 20 2062-2079.

Tsuchida K, Nakatani M, Hitachi K, Uezumi A, Sunada Y, Ageta H \& Inokuchi K 2009 Activin signaling as an emerging target for therapeutic interventions. Cell Communication and Signaling 715.

Vale W, Rivier J, Vaughan J, McClintock R, Corrigan A, Woo W, Karr D \& Spiess J 1986 Purification and characterization of an FSH releasing protein from porcine ovarian follicular fluid. Nature $\mathbf{3 2 1}$ 776-779.

Watanabe M, Masuyama N, Fukuda M \& Nishida E 2000 Regulation of intracellular dynamics of Smad4 by its leucine-rich nuclear export signal. EMBO Reports 1 176-182.

Weiss J, Guendner MJ, Halvorson LM \& Jameson JL 1995 Transcriptional activation of the follicle-stimulating hormone beta-subunit gene by activin. Endocrinology 136 1885-1891.

de Winter JP, Roelen BA, ten Dijke P, van der Burg B \& van den Eijnden-van Raaij AJ 1997 DPC4 (SMAD4) mediates transforming growth factor-betal (TGF-betal) induced growth inhibition and transcriptional response in breast tumour cells. Oncogene 14 1891-1899.

Received in final form 17 February 2010

Accepted 1 April 2010

Made available online as an Accepted Preprint 6 April 2010 